\title{
Naloxone's Effect on Activity-Induced Phase Shifts of Circadian Rhythms
}

\author{
Daniel Janik $^{1} \&$ Margaret Alvarez Brereton ${ }^{1}$ \\ ${ }^{1}$ University of Wisconsin-Eau Claire, USA \\ Correspondance: Daniel Janik, University of Wisconsin-Eau Claire, USA. E-mail: janikds@uwec.edu
}

Received: July 10, 2017

Accepted: July 24, 2017

Online Published: August 15, 2017

doi:10.5539/ijb.v9n4p10

URL: https://doi.org/10.5539/ijb.v9n4p10

\begin{abstract}
Vigorous running in a novel exercise wheel by hamsters during the subjective day results in large (about $3 \mathrm{hr}$ ) phase advances of their circadian rhythms. We administered the opiate receptor antagonist naloxone at $10 \mathrm{mg} / \mathrm{kg}$ and $20 \mathrm{mg} / \mathrm{kg}$ (i.p.) and found that at $20 \mathrm{mg} / \mathrm{kg}$ it significantly reduced phase shifts. This dose of naloxone also reduced the amount of running shown by hamsters in the novel wheel. At the $20 \mathrm{mg} / \mathrm{kg}$ dose, the reduced amount of running resulted in smaller phase shifts. The results are consistent with the hypothesis that nonphotic phase shifts are linked to exercise and arousal in hamsters. However, because high amounts of running were accompanied by phase shifting in animals whose opiate receptors were blocked, the results provide no evidence that the rewarding nature of running in rodents is an important causal factor in nonphotic phase shifting beyond its role in promoting running.
\end{abstract}

Keywords: opiate, naloxone, locomotion, circadian, phase shift, nonphotic, hamster

\section{Introduction}

Nonphotic phase shifting of circadian rhythms often involves physical activity or arousal associated with physical activity (Reebs \& Mrosovsky, 1989a,b; Reebs, Lavery, \& Mrosovsky, 1989). A number of other stimulus situations can lead to nonphotic-like phase shifts or influence entrainment. These include restricted food access (Mistlberger, 1994), opportunity to hoard (Rusak et al., 1988) and interaction with a conspecific (Mrosovsky et al., 1989). The reason these situations cause shifts of circadian rhythms may be that the animals show a prolonged increase in locomotion and general excitement.

The Syrian hamster shows perhaps the most pronounced nonphotic phase shifts. When it is restricted to a novel wheel for three hours in the middle of the subjective day - circadian time (CT) 4-7 - and engaged in voluntary running for most of that period, it consistently shows a $3 \mathrm{hr}$ circadian phase advance (Janik and Mrosovsky, 1993; Mrosovsky et al., 1992). This manipulation, termed a pulse, is easy to carry out, making it a good procedure for studying the underlying mechanisms of nonphotic phase shifts.

Several brain mechanisms underlying nonphotic phase shifts have been identified. A number of studies have shown that the projection to the suprachiasmatic nucleus (SCN) from the intergeniculate leaflet (IGL) is necessary for nonphotic phase shifts to occur (Janik \& Mrosovsky, 1992; Janik \& Mrosovsky 1994) and that neuropeptide-Y is a critical transmitter in that pathway (Biello, Janik and Mrosovsky, 1994). Another potential candidate for involvement in the resetting response, the pretectum, has been identified by a Fos activation study (Mikkelsen, Vrang \& Mrosovsky, 1998).

However, the nature of the connection between exercise one the one hand and the engagement of brain mechanisms on the other is largely unknown. The activity pulse procedure described above is easy and straightforward to carry out, but the response of the animal, once it starts running, may be quite intricate. Various aspects of body function will change, such as autonomic activity, proprioceptive feedback, state of the hypothlamic-pituitary adrenal axis, and body temperture among others. Although various possible mechanisms have been explored, few clear answers have emerged (Mrosovsky, 1996; Hughs \& Piggins, 2012).

One factor that has been hypothesized to be necessary in linking behavioral activity with neural activation during nonphotic shifting is the rewarding nature of running. Previous work has shown that rodents will work for the opportunity to run in a wheel (Collier \& Hirsch, 1971) and that because the running itself is a reward, it reinforces more running (Borer, 1982). Janik and Mrosovsky (1993) suggested that it may be the rewarding nature of 
voluntary running that is important in causing nonphotic shifts. This idea was spurred by the observation that some hamsters that did not run much at room temperature, when put in the cold, ran as much as good runners and shifters at room temperature, but still did not shift. This was interpreted as meaning that these animals were running to stay warm, not because it was rewarding (but see Mistlberger, Marchant, \& Sinclair, 1996). Since opiate systems have been implicated in reward mechanisms (Wise, 1989) we decided to test the hypothesis that the reward associated with voluntary running, as mediated by endogenous opiates, promotes nonphotic phase shifting. To do this we attempted to block opiate receptors with naloxone, a non-specific opiate receptor antagonist with higher affinity for mu receptors than for delta or kappa receptors, while hamsters ran in novel wheels at ZT (Zeitgeber Time) 4-5, the circadian phase at which the largest phase shifts are seen in response to voluntary running (Mrosovsky et al., 1992; Bobrzynska \& Mrosovsky, 1998).

\section{Materials and Methods}

\subsection{Animals and Housing Conditions}

Male Syrian hamsters (Mesocricetus auratus) 31 days old $(\mathrm{n}=19)$ were purchased from Harlan Sprague-Dawley (Madison, WI, USA) and held individually in polypropylene cages $(25 \times 46 \times 20 \mathrm{~cm})$ equipped with stainless steel mesh lids and metal wheels $17.5 \mathrm{~cm}$ in diameter. The wheels were modified by circling plastic mesh (Gutterguard) around the outside of the wheels, similar to Mrosovsky, Salmon, and Vrang (1998). This allows better footing for the animals resulting in more wheel rotations and fewer foot injuries. Rotations were registered as a magnet on the wheel passed a reed switch mounted on the side of the cage. Switch closures were recorded using Datacol III computerized data collection and analysis system (Minimitter Co.; Sunriver, Oregon). Wheel revolutions were grouped in 10 minute bins and the data were not clipped. Ambient temperature was $22 \pm 2{ }^{\circ} \mathrm{C}$ and the light intensity at cage level was about 70 lux. The animals were entrained to a light:dark cycle of 14:10 (LD 14:10) for 17 days before the first activity pulse. The same group of hamsters was used throughout the experiment. Labdiet 5001 Rodent Chow and water were available continuously except during the $3 \mathrm{hr}$ activity pulses. All procedures were approved by the UWEC IACUC under protocol no. 119.

\subsection{Activity Pulse in Novel Wheels}

All activity pulses were carried out at ZT 4 , that is, eight hr before normal dark onset. At this time animals were transferred from their home cages to running wheels that were new to them. These wheels consisted of the same wheel type found in the home cages except the wheels were mounted in a Plexiglas frame from which the hamsters could not escape. The recording method was the same as that used in the home cages.

\subsection{Protocol}

Animals were given an intraperitoneal (i.p.) injection of either $1 \mathrm{mg}$ naloxone (Research Biochemicals Incorporated, Natick, MA) dissolved in $100 \mu \mathrm{L}$ of $0.9 \% \mathrm{NaCl}$ (approximately $10 \mathrm{mg} / \mathrm{kg}$ ) or an equal volume of $0.9 \%$ saline. Immediately after injection, the animals were transferred to novel wheels and the room lights were turned off. Animals remained in the novel wheels for $3 \mathrm{hr}$ after which they were returned to their home cages and remained in constant darkness (DD) for two more days. This is a modification of the Aschoff type II procedure (Aschoff, 1965) that has been used frequently and has been shown to be a valid way of testing for nonphotic phase-shifting (Janik \& Mrosovsky, 1993; Mrosovsky, 1996). Phase shifts obtained in this way are similar in direction and magnitude to those generated under free running conditions. After resetting was measured, the animals were re-entrained to the LD 14:10 cycle for nine days. They were again injected and placed in novel wheels at ZT 4; this time hamsters that received the saline injections for the first pulse were given $1 \mathrm{mg}$ of naloxone and those that previously received naloxone were injected with saline. After two days in DD to assess resetting and nine days in $\mathrm{LD}$ to allow for entrainment, the entire procedure described above was repeated with the same group of hamsters, but this time the naloxone dose used was $20 \mathrm{mg} / \mathrm{kg}$. The doses of naloxone used in these experiments were chosen because opiate antagonists administered in this range of doses are known to reduce voluntary running (Potter et al, 1983) and self stimulation (Shaefer \& Michael, 1990) in rodents.

\subsection{Data Analysis}

Phase shifts were calculated in a manner similar to that described by Janik and Mrosovsky (1993). Activity onset was defined as the first 10-minute period of activity with more than 80 wheel rotations followed by another such period with 40 minutes. Phase shifts were defined as the difference between the time of the activity onset on the day after the 3-hr pulse and the time of the activity onset on the day before the pulse. Data from two animals (one saline treatment and one naloxone treatment) were excluded from the second experiment ( $20 \mathrm{mg} / \mathrm{kg}$ injections) because of recording problems. Over the course of both experiments six animals began running vigorously during the last hr of the 3-hr pulse period and immediately continued to run vigorously when they were returned to their 
home cages. For these six pulses, we added the wheel revolutions accumulated in the first $2 \mathrm{hr}$ after return to the home cage to those accumulated during the pulse to come up with the total for the pulse. We reasoned that if an animal begins to run in a novel wheel during the last hr of a 3-hr pulse beginning at ZT 4, it is really the equivalent of a pulse beginning at ZT 6 . Animals that run vigorously starting at ZT 6 show phase advances of similar magnitude (about $3 \mathrm{hr}$ ) as those that begin running at ZT 4 (Morsovsky et al., 1992; Bobrzynska \& Mrosovsky, 1998).

\section{Results}

Animals that ran more than about 6000 revolutions in the $3 \mathrm{hr}$ pulse typically had phase shifts of about $2.5-3.0 \mathrm{hr}$ or more whether they were treated with the low dose of naloxone, the high dose of naloxone, or saline (Figure 1). The distribution of phase-shifts in relation to how much an animal ran in a novel wheel was typical of the pattern that has been found in other experiments (Janik and Mrosovsky, 1993; Bobyrzynska and Mrosovsky, 1998). There were two main clusters of points, one for animals that ran a lot (about 6000 or more revolutions) in the novel wheels and showed large ( $>1.5 \mathrm{hr}$ ) phase advances and another for animals that ran little (about 3000 revolutions or fewer) and showed small phase advances $(<1.5 \mathrm{hr})$. The phase shifts of only a few animals fell between these clusters. The main exceptions to this generalization were two points [Fig 1(right) -marked with asterisks] that came from one animal who ran vigorously when injected with both saline and naloxone, but failed to show a large shift in either case.
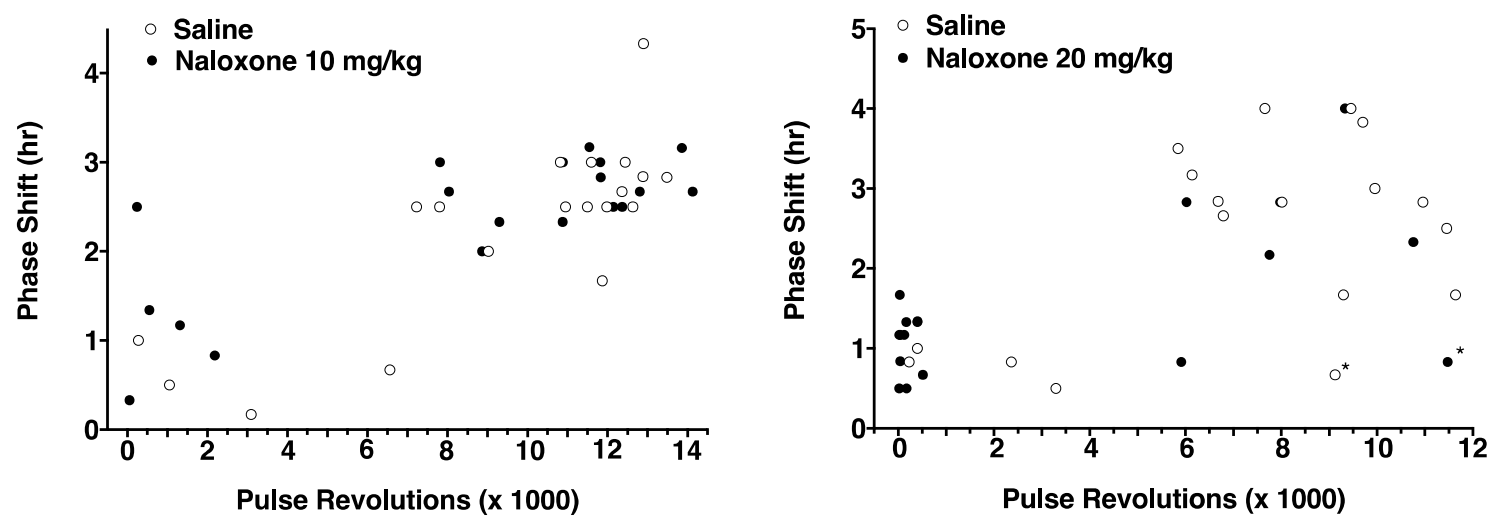

Figure 1. Phase shifts of individual hamsters injected with naloxone or vehicle (saline) as a function of revolutions in a novel wheel during a 3-hr period beginning and ZT 4. The left panel shows data from hamsters injected with $10 \mathrm{mg} / \mathrm{kg}$ naloxone and the right panel shows data from hamsters injected with $20 \mathrm{mg} / \mathrm{kg}$ naloxone. Data points marked with asterisks come from a single animal that exhibited high activity but did not shift regardless of

treatment

When we compared treatment groups for phase-shifting, we found that there was no significant difference between naloxone-treated animals and saline controls at $10 \mathrm{mg} / \mathrm{kg}$ (Fig $2 \mathrm{~A} ; \mathrm{p}=0.82$, t-test), but animals treated with 20 $\mathrm{mg} / \mathrm{kg}$ naloxone showed significantly less phase-shifting than saline-treated animals (Fig 2A; $=.029$, t-test). When we compared the amount of phase-shifting for animals that ran more that 6000 revolutions, we found that there was no significant difference between saline-treated and naloxone-treated animals at either dose (Fig 2B); animals running more than about 6000 revolutions advanced about $2.75 \mathrm{hr}$ regardless of treatment.

To understand how naloxone treatment reduced the amount of phase-shifting, we looked at the amount of running during pulses (Fig 2C). Treatment with $10 \mathrm{mg} / \mathrm{kg}$ naloxone did not reduce the average amount of running, but treatment with $20 \mathrm{mg} / \mathrm{kg}$ naloxone did reduce the average amount of running by about $50 \%$ ( $\mathrm{p}=0.022$; paired t-test). This reduction was achieved mainly by reducing the number of animals that could achieve a minimum of 6000 revolutions, that is, the number of animals that were both good runners and large shifters (see cluster of points in the upper right of Figs 1A and 1B). When we compared the number of animals that ran $>6000$ revolutions or had phase-shifts of $>1.5 \mathrm{hr}$ versus animals that ran $<6000$ revolutions or had phase-shifts of $\leq 1.5 \mathrm{hr}$, we found that 13 of the 18 animals had decreased amounts of pulse running when treated with $20 \mathrm{mg} / \mathrm{kg}$ naloxone as compared to treatment with saline. The sign test (a nonparametric test that compares related samples for the direction of change of a variable; Siegel 1956) applied to these data indicates that the number of animals showing a decrease is significant $(\mathrm{p}=0.048)$. 


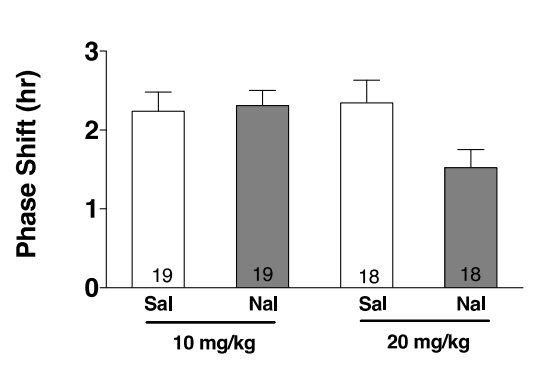

A

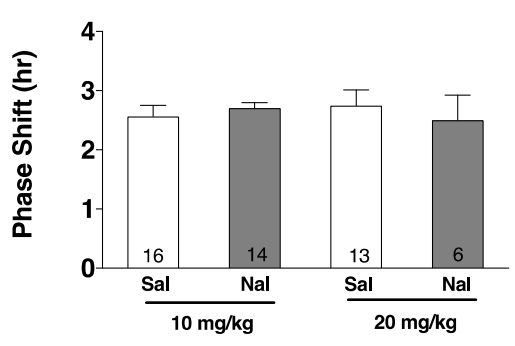

B

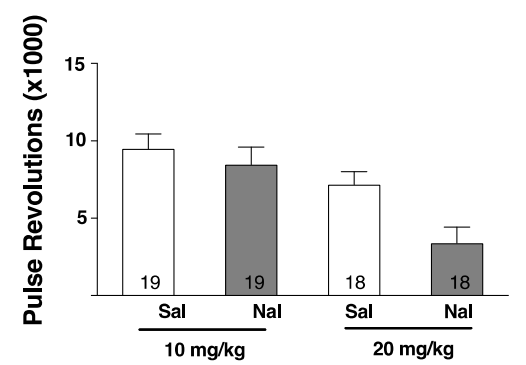

Figure 2. A) The effect of naloxone (Nal) and saline (Sal) on mean ( \pm SEM) phase shift for all hamsters. Nal (20 $\mathrm{mg} / \mathrm{kg}$ ) vs. Sal: $\mathrm{p}=0.029$, paired t-test. B) The effect of Nal and Sal on mean ( \pm SEM) phase shift for hamsters that ran $>6000$ revolutions during the activity pulse. None of the comparisons is significantly different. C) The effect of $\mathrm{Nal}$ and Sal on mean ( \pm SEM) revolutions during a 3-hr activity pulse in a novel wheel. Nal $(20 \mathrm{mg} / \mathrm{kg})$ vs. Sal: $\mathrm{p}$ $=0.022$, paired t-test. Numbers of animals for each treatment are noted at the bottom of the bars

\section{Discussion}

The data in the present experiment indicate a role for endogenous opiates in stimulating running that leads to resetting of circadian rhythms. As a group, hamsters treated with $20 \mathrm{mg} / \mathrm{kg}$ naloxone, a non-specific opiate receptor antagonist, ran significantly less and showed smaller phase advances during $3 \mathrm{hr}$ of confinement to a novel wheel at ZT 4 than saline-injected controls. However, individual hamsters that did run as much as the majority of saline-injected individuals ( $>6000$ revolutions), shifted just as much. Therefore, naloxone's effect on reducing non-photic phase shifts appears to be tightly coupled to its activity-lowering effect.

Previous work by Potter et al. (1983) has shown that blocking opiate receptors reduces voluntary nocturnal running in hamsters. They administered naltrexone, a long-acting opiate receptor antagonist, at a dose of $20 \mathrm{mg} / \mathrm{kg}$ to hamsters and found that it reduced spontaneous nocturnal running, but did not reduce the amount of hypothalamic self-stimulation. The dose of $20 \mathrm{mg} / \mathrm{kg}$ naltrexone used by Potter et al. (1983) and the dose of $20 \mathrm{mg} / \mathrm{kg}$ naloxone used in the present experiment is sufficient to block self-stimulation in rats via electrodes implanted in the midbrain-central gray $(100 \%$ reduction) and medial forebrain bundle-lateral hypothalamus $(60 \%$ reduction) as shown by Schaefer and Michael (1981). Therefore, the doses used in this experiment were almost certainly sufficient to at least partially block opiate systems, although it is unlikely that they were fully blocked for the entire $3 \mathrm{hr}$ pulse because the half-life of naloxone in serum and brain is somewhere around $1 \mathrm{hr}$ (Berkowitz et al., 1975). Our intent in this experiment was to see if by blocking opiate receptors we could reduce phase-shifting independent of activity. At a lower dose $(10 \mathrm{mg} / \mathrm{kg})$ naloxone had no effect on activity-induced phase-shifts or the 
amount of running that leads to shifting. At a higher dose $(20 \mathrm{mg} / \mathrm{kg})$ naloxone lowered both running and shifting, but naloxone-treated hamsters shifted about the same amount as saline-treated hamsters compared to the amount they ran. Therefore, the simplest explanation of why naloxone reduces activity-induced phase-shifts is that it lowers the amount of running generated by a hamster. We hypothesized that the rewarding nature of running (Collier \&Hirsch, 1971; Borer, 1982), as mediated by the opiate system, may be causal in generating nonphotic phases shifts. In a sense, the results of this experiment support this hypothesis to the extent that running - a self-reinforcing (rewarding) behavior - is reduced by opiate blockade. However, this would be a somewhat trivial way of ascribing a role for motivation in phase-shifting. A more meaningful role for reward or motivation would be indicated if opiate blockade reduced phase-shifting in hamsters that ran a lot. This was clearly not the case.

The results of this study also support the conclusions of Marchant and Mistlberger (1995) who showed that mice injected with morphine phase shifted at circadian times which locomotor activity is known to shift circadian rhythms - advances in the middle of the subjective day and delays late in the subjective night. They attributed the shifts to be the result of the acute hyperactivity observed after injection. This was confirmed when morphine-injected animals were prevented from being active and subsequently failed to show significant shifts. Therefore, the present experiment confirms, in a different way and in a species that shows large nonphotic phase-shifts (mice do not show large nonphotic shifts), that opiate systems are involved in nonphotic phase-shifting to the extent that they reinforce and stimulate physical activity which in turn leads to a phase-shift.

Other work has shown that opiate systems may be involved in the nonphotic-like circadian clock resetting. The delta opioid agonist SNC 80 has been shown to induce small (approx. $0.8 \mathrm{hr}$ ) phase advances when administered in the late subjective day (Byku and Gannon 2000a) as has the delta opioid agonist BW373U86 (ca. $0.6 \mathrm{hr}$; Byku and Gannon 2000b). Fentanyl, a mu opioid agonist, also leads to small (ca. $1.0 \mathrm{hr}$ ) phase advances when administered at CT 6 (Vansteensel et al., 2005).

The acute affect agonist administration was not measured in any of these studies. Byku and Gannon (2000a,b) did note that activity levels over a $24 \mathrm{hr}$ period were not systematically changed by the administration of the delta agonists, but there is no evidence that cycle-wide activity levels are important in induced nonphotic phase advances, but rather it is the specific phase at which the activity occurs that matters, namely mid-to-late subjective day. In that light, it is interesting to note that the original actograms depicting delta opioid agonist-induced phase advances by Byku and Gannon (2000 a,b) have large amounts of activity immediately following the injection in the late subjective day. The study looking at fentanyl-induced phase advances (Vansteensel et al., 2005) did not report activity levels of the animals, but the actograms shown in that report do not appear to show increased activity in the mid subjective day acutely linked to the injection. Nevertheless, fentanyl is known to increase activity levels for 2-3 hr after injection, at least in rats (Gillman et al., 2009).

\section{Conclusion}

Blockade of opiate receptors with naloxone reduces the amount of phase-shifting that hamsters show in response to a $3 \mathrm{hr}$ confinement in a novel wheel by reducing the amount of running the animals express. Running in a novel wheel during the subjective day appears to be mediated in part by opiate systems. However, this study provides no evidence that opiate systems are involved in nonphotic phase-shifting independent of their role in mediating running.

\section{Acknowledgments}

This work was supported by grants from the University of Wisconsin-Eau Claire Office of Research and Sponsored Programs and grant RUI IBN 9808866 from the National Science Foundation.

\section{References}

Aschoff, J. (1965). Response curves in circadian periodicity. In J. Aschoff (ed.), Circadian clocks (pp. 95-111). Amsterdam: North-Holland Publishing Co..

Berkowitz, B. A., Ngai, S. H., Hempstead, J., \& Spector, S. J. (1975). Disposition of naloxone: use of a new radioimmunoassay. Pharmacology and Experimental Therapeutics, 195, 499-504.

Biello, S. M., Janik, D., \& Mrosovsky, N. (1994). Neuropeptide Y and behaviorally induced phase shifts. Neuroscience, 62, 273-279. https://doi.org/10.1016/0306-4522(94)90331-X

Bobrzynska, K. J., \& Mrosovsky, N. (1998). Phase shifting by novelty-induced running: activity dose-response curves at different circadian times. Journal of Comparative Physiology A, 182, 251-258. https://doi.org/10.1007/s003590050175 
Borer, K. T. (1982). The nonhomeostatic motivation to run in the golden hamster. In A. R. Morrison, \& P. L. Strick (Eds.), Changing concepts of the nervous system (pp. 539-567). New York: Academic Press. https://doi.org/ 10.1016/B978-0-12-507750-7.50043-3

Byku, M., \& Gannon, R. L. (2000A). SNC 80, a delta-opioid agonist, elicits phase advances in hamster circadian activity rhythms. NeuroReport, 11, 1449-52. https://doi.org/10.1097/00001756-200005150-00019

Byku, M., \& Gannon, R.L. (2000B). Opioid induced non-photic phase shifts of hamster circadian activity rhythms. Brain Research, 873, 189-96. https://doi.org/10.1016/S0006-8993(00)02304-0

Collier, G., \& Hirsch, E. (1971). Reinforcing properties of spontaneous activity in the rat. Journal of Comparative Physiological Psychology, 77, 155-160. https://doi.org/10.1037/h0031588

Gillman, A. G., Leffel, J. K., Ann, E. K., Kosobud, A. E. K., \& Timberlake, W. (2009) Fentanyl, but not haloperidol, entrains persisting circadian activity episodes when administered at 24- and 31-h intervals. Behavioural Brain Research, 205, 102-114. https://doi.org/10.1016/j.bbr.2009.07.002

Hughs, A. T. L., \& Piggins, H. D. (2012). Feedback actions of locomotor activity to the circadian clock. In A. Kalsbeek, M. Merrow, T. Roennenberg, \& R. G. Foster (Eds.) Progress in Brain Research (Vol. 199, pp. 305-336). https://doi.org/10.1016/B978-0-444-59427-3.00018-6

Janik, D., \& Mrosovsky, N. (1992). Gene expression in the geniculate induced by a nonphotic circadian phase shifting stimulus. NeuroReport, 3, 575-578. https://doi.org/10.1097/00001756-199207000-00007

Janik, D., \& Mrosovsky, N. (1993). Nonphotically induced phase shifts of circadian rhythms in the golden hamster: Activity-response curves at different ambient temperatures. Physiology \& Behavior, 53, 431-436. https://doi.org/10.1016/0031-9384(93)90135-3

Janik, D., \& Mrosovsky, N. (1994). Intergeniculate leaflet lesions and behaviorally -induced shifts of circadian rhythms. Brain Research, 651, 174-182. https://doi.org/10.1016/0006-8993(94)90695-5

Marchant, E. G., \& Mistlberger, R. E. (1995). Morphine phase-shifts circadian rhythms in mice: role of $\begin{array}{lllll}\text { behavioural } & \text { Neuroreport, } & 7, & 209-212 & \text { (1995). }\end{array}$ https://doi.org/10.1097/00001756-199512290-00050

Mikkelsen, J. D., Vrang, N., \& Mrosovsky, N. (1998). Expression of Fos in the circadian system following nonphotic stimulation. Brain Research Buletin, 47, 367-376. https://doi.org/10.1016/S0361-9230(98)00 $121-\mathrm{X}$

Mistleberger, R. E., Marchant, E. G., \& Sinclair, S. V. (1996). Nonphotic phase-shifting and the motivation to run: cold exposure reexamined. Journal of Biological Rhythms, 11, 208-215. https://doi.org/10.1177/0748730 49601100303

Mistlberger, R. E. (1994). Circadian food-anticipatory activity: formal models and physiological mechanisms. Neuroscience and Biobehavioral Reviews, 18, 171-195. https://doi.org/10.1016/0149-7634(94)90023-X

Mrosovsky, N. (1996). Locomotor activity and non-photic influences on circadian clocks. Biological Reviews, 71, 343-372. https://doi.org/10.1111/j.1469-185X.1996.tb01278.x

Mrosovsky, N., Salmon, P. A., \& Vrang, N. (1998). Revolutionary science: an improved running wheel for hamsters. Chronobiology International, 15, 147-158. https://doi.org/10.3109/07420529808998679

Mrosovsky, N. (1996). Methods of measuring phase shifts: why I continue to use an Aschoff type II procedure despite the skepticism of referees. Chronobiology International, 13, 387-392. https://doi.org/10.3109/07 420529609012662

Mrosovsky, N., Reebs, S. G, Honrado, G. I., \& Salmon, P.A. (1989). Behavioral entrainment of circadian rhythms. Experientia, 45, 696-702. https://doi.org/10.1007/BF01974561

Mrosovsky, N., Salmon, P., Menaker, M., \& Ralph, M.R. (1992). Nonphotic phase shifting in hamster clock mutants. Journal of Biological Rhythms, 7, 41-49. https://doi.org/10.1177/074873049200700104

Potter, C. D., Borer, K. T., \& Katz, R. J. (1983) Opiate-Receptor blockade reduces voluntary running but not self-stimulation in hamsters. Pharmacology Biochemistry and Behavior, 18, 217-223. https://doi.org/10. 1016/0091-3057(83)90366-0

Reebs, S. G., Lavery, R. J., \& Mrosovsky, N. (1989). Running activity mediates the phase-advancing effects of dark pulses on hamster and circadian rhythms. Journal of Comparative Physiology A, 165, 811-818. https://doi.org/10.1007/BF00610879 
Reebs, S. G., \& Mrosovsky, N. (1989a). Effects of induced wheel running on the circadian activity rhythms of syrian hamsters: entrainment and phase response curve. Journal of Biological Rhythms, 4, 39-48. https://doi.org/10.1177/074873048900400103

Reebs, S. G., \& Mrosovsky, N. (1989b). Large phase-shifts of circadian rhythms caused by the induced running in a re-entrainment paradigm: the role of pulse duration and light. Journal of Comparative Physiology A, 165, 819-825. https://doi.org/10 .1007/BF00610880

Rusak, B., Mistlberger, R. E., Losier, B., \& Jones, C. H. (1988). Daily hoarding opportunity entrains the pacemaker for hamster activity rhythms. Journal of Comparative Physiology A, 164, 165-171. https://doi.org/10.1007/BF00603948

Schaefer, G. J., \& Michael, R. P. (1990) Interactions of naloxone with morphine, amphetamine and phencyclidine on on fixed interval responding for intracranial self-stimulation in rats. Psychopharmacology, 102, 263. https://doi.org/10.1007/BF02245931

Siegel, S. (1956). Nonparametric Statistics for the Behavioral Sciences. McGraw-Hill, NY.

Vansteensel, M. J., Magnone, M. C., van Oosterhout, F., Baeriswyl, S., Albrecht, U., Albus, H., ... Meijer J. H. (2005). The opioid fentanyl affects light input, electrical activity and Per gene expression in the hamster suprachiasmatic nuclei. European Journal of Neuroscience, 21, 2958-66. https://doi.org/10.1111/j.1460 -9568.2005.04131.x

Wise, R. A. (1989). Opiate reward: sites and substrates. Neuroscience and Biobehavioral Reviews, 13, 129-133. https://doi.org/10.1016/S0149-7634(89)80021-1

\section{Copyrights}

Copyright for this article is retained by the author(s), with first publication rights granted to the journal.

This is an open-access article distributed under the terms and conditions of the Creative Commons Attribution license (http://creativecommons.org/licenses/by/4.0/). 